\title{
Commentary \\ Kidney function assessment in the critically ill child: is it time to leave creatinine behind?
}

\author{
Stuart L Goldstein
}

Texas Children's Hospital, 6621 Fannin Street, MC 3-2482, Houston, TX 77030, USA

Corresponding author: Stuart L Goldstein, stuartg@bcm.edu

Published: 15 June 2007

Critical Care 2007, 11:141 (doi:10.1186/cc5935)

This article is online at http://ccforum.com/content/11/3/141

(c) 2007 BioMed Central Ltd

See related research by Herrero-Morin et al., http://ccforum.com/content/11/3/R59

\begin{abstract}
The accurate diagnosis of acute kidney injury (AKI) is especially problematic in critically ill patients in whom renal function is in an unsteady state, rendering creatinine-based baseline assessment measures of renal function potentially inadequate. Herrero-Morin and colleagues performed a cross-sectional analysis of the ability of cystatin $C$ and $\beta_{2}$ microglobulin to reflect creatinine clearance in pediatric patients with AKI. The aim of this commentary is to review the current state of AKI clinical and translational research in the light of the results presented in that study.
\end{abstract}

Current standard assessments of renal function for pediatric patients use serum creatinine or formulas based on serum creatinine designed for longitudinal assessment of baseline renal function. The accurate diagnosis of acute kidney injury (AKI) is especially problematic in critically ill patients in whom renal function is in an unsteady state, thus rendering such creatinine-based baseline assessment measures of renal function potentially inadequate. Pediatric patients comprise a valuable cohort for study, because they usually do not carry many of the co-morbidities that often confound adult patient studies. In this issue of Critical Care, Herrero-Morin and colleagues assess the ability of two markers, cystatin $\mathrm{C}$ and $\beta_{2}$ microglobulin $\left(\beta_{2} M\right)$, to detect decreases in renal function accurately in 25 critically ill children [1].

The authors conducted a careful study to obtain 24-hour urine collections of creatinine clearance before obtaining serum $\beta_{2} \mathrm{M}$ and cystatin $\mathrm{C}$ samples. Fourteen (56\%) developed AKI, which they defined as a creatinine clearance of less than $80 \mathrm{ml} / \mathrm{min}$ per $1.73 \mathrm{~m}^{2}$. Their primary results demonstrated thresholds for both $\beta_{2} \mathrm{M}(1.5 \mathrm{mg} / \mathrm{l})$ and cystatin $\mathrm{C}(0.6 \mathrm{mg} / \mathrm{l})$ that exhibited reasonable sensitivity and specificity to detect AKI accurately, whereas serum creatinine was no different between patients with and without AKI. The present study is therefore the first report of non-creatinine-based methods to estimate renal function in critically ill pediatric patients with AKI.

The rationale for assessing AKI markers in critically ill patients is strong. Numerous studies demonstrate that AKI is an independent risk factor for mortality, so critically ill patients are dying from and not just 'with' AKI. Until recently, pediatric AKI studies used the Schwartz formula [2], a creatininebased equation designed to assess baseline renal function [3]. The need for accurate and sensitive description of AKI has led to the development of a multidimensional AKI classification system, which in essence grades AKI severity. The most widely referenced system is the RIFLE (Risk, Injury, Failure, Loss, End-stage kidney disease) criteria, proposed as an empiric system by the Acute Dialysis Quality Initiative [4]. Hoste and colleagues validated the RIFLE criteria in critically ill adult patients, finding that patients with maximum RIFLE class $\mathrm{R}$, class $\mathrm{I}$ and class $\mathrm{F}$ had hospital mortality rates of $8.8 \%, 11.4 \%$ and $26.3 \%$, respectively [5]. Our center recently reported similar results for pediatric modified RIFLE criteria in a pediatric cohort of critically ill children: AKI by pediatric RIFLE during admission was an independent predictor of intensive care, hospital length of stay and an increased risk of death independent of the Pediatric Risk of Mortality (PRISM II) score (odds ratio 3.0) [6].

Early recognition of $\mathrm{AKI}$, before changes in serum creatinine occur, has been an area of intensive investigation over the past 5 years. The rationale for such research emanates from studies demonstrating that even small increases in serum creatinine are associated with increases in patient morbidity and mortality. Chertow found a 6.5 -fold increase in the odds of death for patients with a $0.5 \mathrm{mg} / \mathrm{dl}$ increase in serum creatinine, even when adjusted for numerous co-morbidities [7]. We have found a sevenfold increase in the odds of death in

$A K I=$ acute kidney injury; $\beta_{2} M=\beta_{2}$ microglobulin; GFR = glomerular filtration rate; RIFLE = Risk, Injury, Failure, Loss, End-stage kidney disease. 
pediatric patients with acute decompensated heart failure who had an serum creatinine increase of $0.3 \mathrm{mg} / \mathrm{dl}$ or more [8].

Cystatin C is a logical marker for AKI study because its concentration is not affected by muscle mass and it is not secreted by the renal tubule; it is therefore a potentially more accurate and earlier marker of change in glomerular filtration rate (GFR) than serum creatinine. Herget-Rosenthal and colleagues found increases in serum cystatin C 11/2 days before AKI development (defined as attaining RIFLE-R [9]), and the same group found serum cystatin $C$ to detect

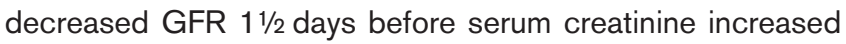
in patients undergoing unilateral nephrectomy for kidney donation [10]. Because both cystatin $C$ and $\beta_{2} M$ in the current study by Herrero-Morin differed between patients with and without $\mathrm{AKI}$, whereas serum creatinine did not differ, a reasonable inference could be that serum $\beta_{2} \mathrm{M}$ and cystatin $C$ detect renal injury before changes in serum creatinine. However, the present study was not designed to assess for earlier AKI recognition. Further study of these two markers, along with potential urinary AKI biomarkers currently under investigation, including NGAL (neutrophil gelatinase-associated lipocalin) [11], interleukin-18 [12] and KIM-1 (kidney injury molecule-1) [13], is required in pediatric patients to develop a panel of markers for the accurate and reliable assessment of early $\mathrm{AKI}$ development, $\mathrm{AKI}$ duration and site of injury. So, is it time to leave serum creatinine behind as a marker of renal function in patients with AKI? Currently, the answer is no, but the work of Herrero-Morin and colleagues argues strongly for the study of other markers, including cystatin $C$ and $\beta_{2} M$, in the near future.

\section{Competing interests}

The author declares that they have no competing interests.

\section{References}

1. Herrero-Morin JD, Malaga S, Fernandez N, Rey C, Dieguez MA, Solis G, Concha A, Medina A: Cystatin C and beta2-microglobulin: markers of glomerular filtration in critically ill children. Crit Care 2007, 11:R59.

2. Schwartz GJ, Brion LP, Spitzer A: The use of plasma creatinine concentration for estimating glomerular filtration rate in infants, children, and adolescents. Pediatr Clin North Am 1987, 34:571-590.

3. Hui-Stickle S, Brewer ED, Goldstein SL: Pediatric ARF epidemiology at a teritary care center from 1999 to 2001. Am J Kidney Dis 2005, 45:96-101.

4. Bellomo R, Ronco C, Kellum JA, Mehta RL, Palevsky P: Acute renal failure - definition, outcome measures, animal models, fluid therapy and information technology needs: the Second International Consensus Conference of the Acute Dialysis Quality Initiative (ADQI) Group. Crit Care 2004, 8:R204-R212.

5. Hoste EA, Clermont G, Kersten A, Venkataraman R, Angus DC, De Bacquer D, Kellum JA: RIFLE criteria for acute kidney injury are associated with hospital mortality in critically ill patients: a cohort analysis. Crit Care 2006, 10:R73.

6. Akcan-Arikan A, Zappitelli M, Loftis LL, Washburn KK, Jefferson LS, Goldstein SL: Modified RIFLE criteria in critically ill children with acute kidney injury. Kidney Int 2007, 71:1028-1035.

7. Chertow GM, Burdick E, Honour M, Bonventre JV, Bates DW: Acute kidney injury, mortality, length of stay, and costs in hospitalized patients. J Am Soc Nephro/ 2005, 16:3365-3370.

8. Goldstein SL, Denfield S, Mott A, Chang A, Towbin J, Dickerson $H$, Dreyer J, Price J: 'Mild' renal insufficiency is associated with poor outcome in children with acute decompensated heart failure: evidence for a pediatric cardiorenal syndrome [abstract]. J Am Soc Nephrol 2005, 16:534A.

9. Herget-Rosenthal S, Marggraf G, Husing J, Goring F, Pietruck F, Janssen $O$, Philipp T, Kribben A: Early detection of acute renal failure by serum cystatin C. Kidney Int 2004, 66:1115-1122.

10. Herget-Rosenthal S, Pietruck F, Volbracht L, Philipp T, Kribben A: Serum cystatin C - a superior marker of rapidly reduced glomerular filtration after uninephrectomy in kidney donors compared to creatinine. Clin Nephrol 2005, 64:41-46.

11. Mishra J, Dent C, Tarabishi R, Mitsnefes MM, Ma O, Kelly C, Ruff SM, Zahedi K, Shao M, Bean J, et al:: Neutrophil gelatinaseassociated lipocalin (NGAL) as a biomarker for acute renal injury after cardiac surgery. Lancet 2005, 365:1231-1238.

12. Parikh CR, Jani A, Melnikov VY, Faubel S, Edelstein CL: Urinary interleukin-18 is a marker of human acute tubular necrosis. Am J Kidney Dis 2004, 43:405-414.

13. Han WK, Bailly V, Abichandani R, Thadhani R, Bonventre JV: Kidney injury molecule-1 (KIM-1): a novel biomarker for human renal proximal tubule injury. Kidney Int 2002, 62:237244. 